\title{
APPROXIMATION OF FIXED POINTS OF STRONGLY PSEUDOCONTRACTIVE MAPPINGS IN UNIFORMLY SMOOTH BANACH SPACES
}

\author{
XUE ZHIQUN
}

Received 3 March 2005; Revised 21 March 2006; Accepted 4 April 2006

Let $E$ be a real uniformly smooth Banach space, and $K$ a nonempty closed convex subset of $E$. Assume that $T_{1}+T_{2}: K \rightarrow K$ is a continuous and strongly pseudocontractive mapping, where $T_{1}: K \rightarrow K$ is Lipschitz and $T_{2}: K \rightarrow K$ has the bounded range mapping. Then the Ishikawa iterative sequence converges strongly to the unique fixed point of $T_{1}+T_{2}$.

Copyright (c) 2006 Hindawi Publishing Corporation. All rights reserved.

\section{Introduction}

Let $E$ be an arbitrary real Banach space and $E^{*}$ the dual space on $E$. The normalized duality mapping $J: E \rightarrow 2^{E^{*}}$ is defined by

$$
J x=\left\{f \in E^{*}:\langle x, f\rangle=\|x\| \cdot\|f\|=\|f\|^{2}\right\},
$$

for all $x \in E$, where $\langle\cdot, \cdot\rangle$ denotes the generalized duality pairing. It is well known that if $E$ is a uniformly smooth Banach space, then $J$ is single valued such that $J(-x)=-J(x)$, $J(t x)=t J(x)$ for all $t \geq 0, x \in E$; and $J$ is uniformly continuous on any bounded subset of $E$. In the sequel we will denote single-valued normalized duality mapping by $j$. In the following we give some concepts.

Let $T: D(T) \rightarrow E$ be a mapping with domain $D(T)$ and range $R(T)$. A mapping $T$ is said to be pseudocontractive if for any $x, y \in D(T)$ there exists $j(x-y) \in J(x-y)$ such that

$$
\langle T x-T y, j(x-y)\rangle \leq\|x-y\|^{2} .
$$

The mapping $T$ is said to be strongly pseudocontractive if for any $x, y \in D(T)$ there exists $j(x-y) \in J(x-y)$ such that

$$
\langle T x-T y, j(x-y)\rangle \leq k\|x-y\|^{2}
$$

for some constant $k \in(0,1)$.

Hindawi Publishing Corporation

International Journal of Mathematics and Mathematical Sciences

Volume 2006, Article ID 46561, Pages 1-6

DOI 10.1155/IJMMS/2006/46561 
Recently, Zhou and Jia [5] proved the following result: let $E$ be a real Banach space with a uniformly convex dual $E^{*}$, and let $K$ be a nonempty closed convex and bounded subset of $E$. Assume that $T: K \rightarrow K$ is a continuous and strong pseudocontraction, the Ishikawa iteration sequence $\left\{x_{n}\right\}_{n=1}^{\infty}$ generated by (IS) converges strongly to the unique fixed point of $T$. However, when $T$ is continuous strongly pseudocontractive mapping, one question arises naturally: if $T$ neither is Lipschitzian nor has the bounded range, whether or not the Ishikawa iterative sequence $\left\{x_{n}\right\}_{n=1}^{\infty}$ generated converges strongly to the unique fixed point of $T$. It is our purpose in this note to solve the above question by proving the following much more general result: $E$ is a real uniformly smooth Banach space, and $K$ is a nonempty closed convex subset of $E$. Assume that $T: K \rightarrow K$ is a continuous and strong pseudocontraction, and $T$ neither is Lipschizian nor has the bounded range, then the Ishikawa iteration sequence converges strongly to the unique fixed point of $T$.

Lemma 1.1 [5]. Let $E$ be a real Banach space, then for all $x, y \in E$, there exists $j(x+y) \in$ $J(x+y)$ such that

$$
\|x+y\|^{2} \leq\|x\|^{2}+2\langle y, j(x+y)\rangle .
$$

LEMma 1.2 [5]. Let $\left\{\rho_{n}\right\}_{n=1}^{\infty}$ be a nonnegative real sequence satisfying

$$
\rho_{n+1} \leq\left(1-\lambda_{n}\right) \rho_{n}+\sigma_{n}
$$

where $\lambda_{n} \in[0,1], \sum_{n=1}^{\infty} \lambda_{n}=\infty$ and $\sigma_{n}=o\left(\lambda_{n}\right)$. Then $\rho_{n} \rightarrow 0$ as $n \rightarrow \infty$.

\section{Main results}

Now we prove the main results of this note, In the sequel, we always assume that $E$ is a real uniformly smooth Banach space.

Theorem 2.1. Let $K$ be a nonempty closed convex subset of E. Assume that $T_{1}+T_{2}: K \rightarrow K$ is a continuous and strongly pseudocontractive mapping, where $T_{1}: K \rightarrow K$ is Lipschitz and $T_{2}: K \rightarrow K$ has the bounded range mapping. Let $\left\{\alpha_{n}\right\}_{n=1}^{\infty}$ and $\left\{\beta_{n}\right\}_{n=1}^{\infty}$ be two real sequences in $[0,1]$ satisfying the following conditions: (i) $\alpha_{n}, \beta_{n} \rightarrow 0$ as $n \rightarrow \infty$; (ii) $\sum_{n=1}^{\infty} \alpha_{n}=\infty$. Then the Ishikawa iterative sequence generated from an arbitrary $x_{1} \in K$ by (IS1),

$$
\begin{gathered}
x_{n+1}=\left(1-\alpha_{n}\right) x_{n}+\alpha_{n}\left(T_{1}+T_{2}\right) y_{n}, \\
y_{n}=\left(1-\beta_{n}\right) x_{n}+\beta_{n}\left(T_{1}+T_{2}\right) x_{n},
\end{gathered}
$$

converges strongly to the unique fixed point of $T_{1}+T_{2}$.

Proof. The existence of a fixed point follows from Deimling [4]. Let $q$ be a fixed point of $T_{1}+T_{2}$. Since $T_{1}+T_{2}$ is strongly pseudocontractive, thus for all $x, y \in K$,

$$
\left\langle\left(T_{1}+T_{2}\right) x-\left(T_{1}+T_{2}\right) y, J(x-y)\right\rangle \leq k\|x-y\|^{2},
$$

where $k \in(0,1)$. Then we may get that $q$ must be unique fixed point of $T_{1}+T_{2}$. Let $L$ denote the Lipschitzian constant of $T_{1}, M=\sup _{x \in K}\left\{\left\|T_{2} x-T_{2} q\right\|\right\}, T=T_{1}+T_{2}$. Using 
(2.1), we have

$$
\begin{aligned}
\left\|y_{n}-q\right\| & \leq\left(1-\beta_{n}\right)\left\|x_{n}-q\right\|+\beta_{n}\left(\left\|T_{1} x_{n}-T_{1} q\right\|+\left\|T_{2} x_{n}-T_{2} q\right\|\right) \\
& \leq\left(1-\beta_{n}\right)\left\|x_{n}-q\right\|+\beta_{n}\left(L\left\|x_{n}-q\right\|+M\right) \\
& \leq\left(1-\beta_{n}+\beta_{n} L\right)\left\|x_{n}-q\right\|+\beta_{n} M .
\end{aligned}
$$

Set $A_{n}=\left\|J\left(\left(x_{n+1}-q\right) /\left(1+\left\|x_{n}-q\right\|\right)\right)-J\left(\left(y_{n}-q\right) /\left(1+\left\|x_{n}-q\right\|\right)\right)\right\|, D_{n}=\| J\left(\left(y_{n}-q\right) /(1+\right.$ $\left.\left.\left\|x_{n}-q\right\|\right)\right)-J\left(\left(x_{n}-q\right) /\left(1+\left\|x_{n}-q\right\|\right)\right) \|$, then $A_{n} \rightarrow 0, D_{n} \rightarrow 0$ as $n \rightarrow \infty$. Indeed $\left\{\left(y_{n}-\right.\right.$ $\left.q) /\left(1+\left\|x_{n}-q\right\|\right)\right\},\left\{\left(x_{n}-q\right) /\left(1+\left\|x_{n}-q\right\|\right)\right\}$, and $\left\{\left(x_{n+1}-q\right) /\left(1+\left\|x_{n}-q\right\|\right)\right\}$ are all bounded, using that $\mathrm{J}$ is uniformly continuous on bounded subset, hence $A_{n} \rightarrow 0$ as $n \rightarrow \infty$ and $D_{n} \rightarrow 0$ as $n \rightarrow \infty$. Applying Lemma 1.1, we obtain

$$
\begin{aligned}
\left\|x_{n+1}-q\right\|^{2}= & \left\|\left(1-\alpha_{n}\right)\left(x_{n}-q\right)+\alpha_{n}\left(T y_{n}-T q\right)\right\|^{2} \\
\leq & \left(1-\alpha_{n}\right)^{2}\left\|x_{n}-q\right\|^{2}+2 \alpha_{n}\left\langle T y_{n}-T q, J\left(x_{n+1}-q\right)\right\rangle \\
\leq & \left(1-\alpha_{n}\right)^{2}\left\|x_{n}-q\right\|^{2}+2 \alpha_{n}\left\langle T y_{n}-T q, J\left(y_{n}-q\right)\right\rangle \\
& +2 \alpha_{n}\left\langle T y_{n}-T q, J\left(x_{n+1}-q\right)-J\left(y_{n}-q\right)\right\rangle \\
\leq & \left(1-\alpha_{n}\right)^{2}\left\|x_{n}-q\right\|^{2}+2 \alpha_{n} k\left\|y_{n}-q\right\|^{2} \\
& +2 \alpha_{n}\left\langle T y_{n}-T q, J\left(\frac{x_{n+1}-q}{1+\left\|x_{n}-q\right\|}\right)-J\left(\frac{y_{n}-q}{1+\left\|x_{n}-q\right\|}\right)\right\rangle \\
& \times\left(1+\left\|x_{n}-q\right\|\right) \\
\leq & \left(1-\alpha_{n}\right)^{2}\left\|x_{n}-q\right\|^{2}+2 \alpha_{n} k\left\|y_{n}-q\right\|^{2} \\
& +2 \alpha_{n} A_{n}\left(L\left\|y_{n}-q\right\|+M\right)\left(1+\left\|x_{n}-q\right\|\right) .
\end{aligned}
$$

Again using Lemma 1.1, we obtain

$$
\begin{aligned}
\left\|y_{n}-q\right\|^{2}= & \left\|\left(1-\beta_{n}\right)\left(x_{n}-q\right)+\beta_{n}\left(T x_{n}-T q\right)\right\|^{2} \\
\leq & \left(1-\beta_{n}\right)^{2}\left\|x_{n}-q\right\|^{2}+2 \beta_{n}\left\langle T x_{n}-T q, J\left(y_{n}-q\right)\right\rangle \\
\leq & \left(1-\beta_{n}\right)^{2}\left\|x_{n}-q\right\|^{2}+2 \beta_{n}\left\langle T x_{n}-T q, J\left(y_{n}-q\right)-J\left(x_{n}-q\right)\right\rangle \\
& +2 \beta_{n}\left\langle T x_{n}-T q, J\left(x_{n}-q\right)\right\rangle \\
\leq & \left(1-\beta_{n}\right)^{2}\left\|x_{n}-q\right\|^{2}+2 \beta_{n}\left\langle T x_{n}-T q, J\left(\frac{y_{n}-q}{1+\left\|x_{n}-q\right\|}\right)-J\left(\frac{x_{n}-q}{1+\left\|x_{n}-q\right\|}\right)\right\rangle \\
& \times\left(1+\left\|x_{n}-q\right\|\right)+2 k \beta_{n}\left\|x_{n}-q\right\|^{2} \\
\leq & \left(\left(1-\beta_{n}\right)^{2}+2 k \beta_{n}\right)\left\|x_{n}-q\right\|^{2} \\
& +2 \beta_{n}\left(\left\|T_{1} x_{n}-T_{1} q\right\|+\left\|T_{2} x_{n}-T_{2} q\right\|\right) D_{n}\left(1+\left\|x_{n}-q\right\|\right)
\end{aligned}
$$


4 Approximation of fixed point mappings in Banach spaces

$$
\begin{aligned}
\leq & \left(\left(1-\beta_{n}\right)^{2}+2 k \beta_{n}\right)\left\|x_{n}-q\right\|^{2} \\
& +2 \beta_{n}\left(L\left\|x_{n}-q\right\|+M\right) D_{n}\left(1+\left\|x_{n}-q\right\|\right) \\
\leq & \left(\left(1-\beta_{n}\right)^{2}+2 k \beta_{n}\right)\left\|x_{n}-q\right\|^{2}+2 \beta_{n}(L+M)\left(1+\left\|x_{n}-q\right\|\right)^{2} \\
\leq & \left(\left(1-\beta_{n}\right)^{2}+2 k \beta_{n}\right)\left\|x_{n}-q\right\|^{2}+4 \beta_{n}(L+M)\left(1+\left\|x_{n}-q\right\|^{2}\right) \\
\leq & \left(\left(1-\beta_{n}\right)^{2}+2 k \beta_{n}+4 \beta_{n}(L+M)\right)\left\|x_{n}-q\right\|^{2}+4 \beta_{n}(L+M) .
\end{aligned}
$$

Furthermore, we have the following estimates to a part of (2.4):

$$
\begin{aligned}
2 \alpha_{n} A_{n} & \left(L\left\|y_{n}-q\right\|+M\right)\left(1+\left\|x_{n}-q\right\|\right) \\
\leq & 2 \alpha_{n} L A_{n}\left(1-\beta_{n}+\beta_{n} L\right)\left\|x_{n}-q\right\|\left(L M A_{n} \beta_{n}+M A_{n}\right)\left(1+\left\|x_{n}-q\right\|\right) \\
\leq & 2 L A_{n} \alpha_{n}\left(1-\beta_{n}+\beta_{n} L\right)\left\|x_{n}-q\right\|^{2}+2 M \alpha_{n} A_{n}\left(L \beta_{n}+1\right) \\
& +2 L A_{n} \alpha_{n}\left(1-\beta_{n}+\beta_{n} L\right)+2 M A_{n} \alpha_{n}\left(L \beta_{n}+1\right)\left\|x_{n}-q\right\| \\
\leq & (2 L+M) A_{n} \alpha_{n}\left(1+\beta_{n} L\right)\left\|x_{n}-q\right\|^{2}+(3 L+M) A_{n} \alpha_{n}\left(1+L \beta_{n}\right) \\
\leq & E_{n}\left\|x_{n}-q\right\|^{2}+E_{n},
\end{aligned}
$$

where $E_{n}=(3 L+M) A_{n} \alpha_{n}\left(1+L \beta_{n}\right)$. Substituting (2.5) and (2.6) in (2.4), we have

$$
\begin{aligned}
\left\|x_{n+1}-q\right\|^{2} \leq & \left(\left(1-\alpha_{n}\right)^{2}+2 \alpha_{n} k\left(\left(1-\beta_{n}\right)^{2}+2 k \beta_{n}+4 \beta_{n}(L+M)\right)+E_{n}\right)\left\|x_{n}-q\right\|^{2} \\
& +8 k \alpha_{n} \beta_{n}(L+M)+E_{n}=\left(1-2(1-k) \alpha_{n}+F_{n}\right)\left\|x_{n}-q\right\|^{2}+G_{n}
\end{aligned}
$$

where $F_{n}=\alpha_{n}^{2}-4 k \alpha_{n} \beta_{n}+2 k \alpha_{n} \beta_{n}^{2}+4 k^{2} \alpha_{n} \beta_{n}+8 k \alpha_{n} \beta_{n}(L+M)+2 k \alpha_{n} E_{n}, G_{n}=8 k(L$ $+M) \alpha_{n} \beta_{n}+E_{n}$, then $F_{n}=o\left(\alpha_{n}\right), G_{n}=o\left(\alpha_{n}\right)$. Hence, we may choose a large positive integer $N$ such that for all $n \geq N$,

$$
F_{n}<\frac{1-k}{2} \alpha_{n}
$$

Thus the above inequality (2.7) yields

$$
\left\|x_{n+1}-q\right\|^{2} \leq\left(1-\frac{3(1-k)}{2} \alpha_{n}\right)\left\|x_{n}-q\right\|^{2}+G_{n} .
$$

By Lemma 1.2 we see that as $\left\|x_{n}-q\right\| \rightarrow 0$ as $n \rightarrow \infty$. The proof of theorem is completed.

Remark 2.2. Concrete the following example: let $E=(-\infty,+\infty), K=[0,+\infty)$, where $\|x\|=|x|, x \in E$. Let $T_{1}: K \rightarrow K$ be defined by $T_{1} x=x / 3$, and let $T_{2}: K \rightarrow K$ be defined 
by

$$
T_{2} x= \begin{cases}-\frac{\sqrt{\left(1-(x-1)^{2}\right)}}{3}, & \text { if } x \in[0,1], \\ -\frac{1}{3}, & \text { if } x \in(1,+\infty)\end{cases}
$$

Then $T_{1}$ is Lipschitz, $T_{2}$ has the bounded range, and $T_{1}+T_{2}$ is strongly pseudocontractive mapping. But $T_{1}+T_{2}$ neither is Lipschitzian nor has a bounded range.

Remark 2.3. Theorem 2.1 contains a good number of the known results as its special cases. In particular, if the mapping $T$ considered here satisfies one of the following assumptions: (i) $T: K \rightarrow K$ is a Lipschitzian; (ii) $T$ has the bounded range, then $T$ satisfied the conditions of Theorem 2.1.

Remark 2.4. In [1], Bogin proved that $T$ is strongly pseudocontractive if and only if ( $I-$ $T$ ) is strongly accretive, where $I$ denotes the identity operator. It is well known that if $T$ is continuous and strongly accretive, then $T$ is surjective, so that, for any given $f \in E$, the equation $T x=f$ has unique solution.

Theorem 2.5. Assume that $T=T_{1}+T_{2}: E \rightarrow E$ is a continuous strongly accretive operator, where $T_{1}: E \rightarrow E$ is Lipschitz, $T_{2}: E \rightarrow E$ has the bounded range operator. For any given $f \in E$, define $S: E \rightarrow E$ by $S x=f-T x+x$ for all $x \in E$. Let $\left\{\alpha_{n}\right\}_{n=1}^{\infty}$ and $\left\{\beta_{n}\right\}_{n=1}^{\infty}$ be two real sequences $[0,1]$ in satisfying the conditions: (i) $\alpha_{n}, \beta_{n} \rightarrow 0$ as $n \rightarrow \infty$; (ii) $\sum_{n=1}^{\infty} \alpha_{n}=\infty$. Then the Ishikawa iterative sequence generated from an arbitrary $x_{1} \in E$ by (IS2),

$$
\begin{gathered}
x_{n+1}=\left(1-\alpha_{n}\right) x_{n}+\alpha_{n} S y_{n}, \\
y_{n}=\left(1-\beta_{n}\right) x_{n}+\beta_{n} S x_{n},
\end{gathered}
$$

converges strongly to the unique solution of the equation $T x=f$.

Proof. By virtue of Remark 2.3, the equation $T x=f$ has unique solution. Set $S_{1} x=x-$ $T_{1} x, S_{2} x=-T_{2} x, x \in E$. Then $S_{1}$ is Lipschitz, $S_{2}$ has the bounded range operator, and $S x=S_{1} x+S_{2} x+f$. Hence $S$ is a continuous and strongly pseudocontractive mapping. We obtain directly the conclusion from Theorem 2.1 .

\section{Acknowledgments}

The author is highly grateful to the referee for valuable comments and good suggestions for improving the note. This project is supported by the National Science Foundation of China and Shijiazhuang Railway College Sciences Foundation.

\section{References}

[1] J. Bogin, On strict pseudo-contractions and a fixed point theorem, Technion Preprint MT-29, Haifa, 1974.

[2] C. E. Chidume, Approximation of fixed points of strongly pseudocontractive mappings, Proceedings of the American Mathematical Society 120 (1994), no. 2, 545-551. 


\section{Approximation of fixed point mappings in Banach spaces}

[3] C. E. Chidume and M. O. Osilike, Ishikawa iteration process for nonlinear Lipschitz strongly accretive mappings, Journal of Mathematical Analysis and Applications 192 (1995), no. 3, 727-741.

[4] K. Deimling, Zeros of accretive operators, Manuscripta Mathematica 13 (1974), no. 4, 365-374.

[5] H. Zhou and Y. Jia, Approximation of fixed points of strongly pseudocontractive maps without Lipschitz assumption, Proceedings of the American Mathematical Society 125 (1997), no. 6, 17051709.

Xue Zhiqun: Department of Mathematics, Shijiazhuang Railway College,

Shijiazhuang 050043, China

E-mail address: xuezhiqun@126.com 


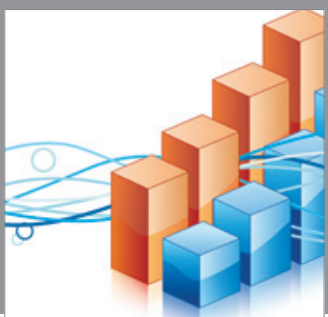

Advances in

Operations Research

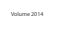

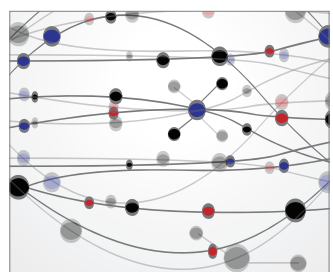

\section{The Scientific} World Journal
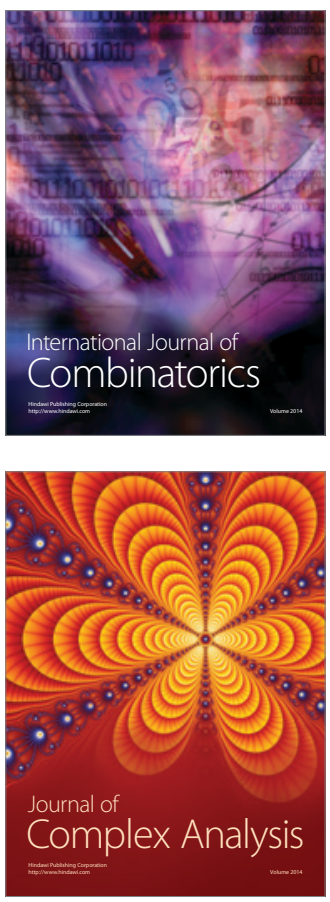

International Journal of

Mathematics and

Mathematical

Sciences
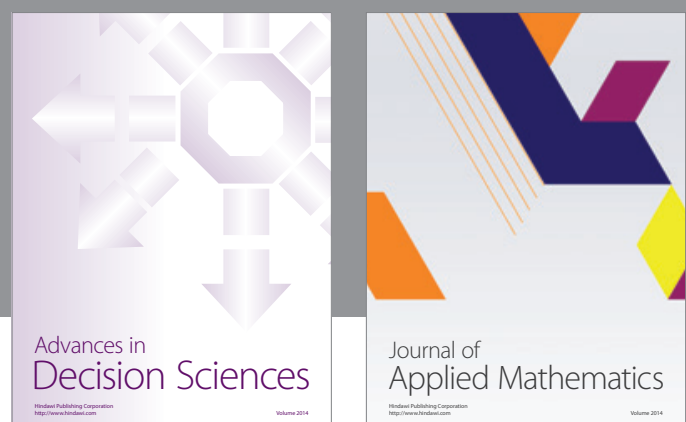

Journal of

Applied Mathematics
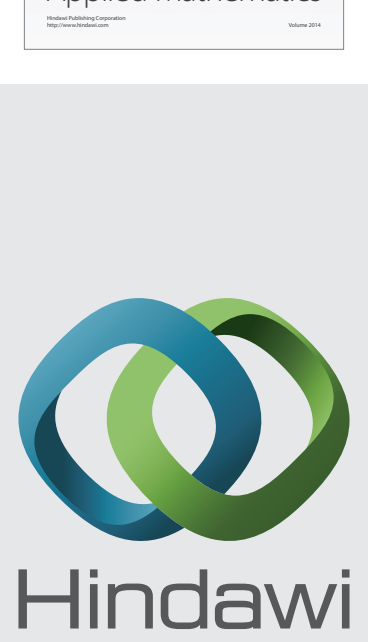

Submit your manuscripts at http://www.hindawi.com
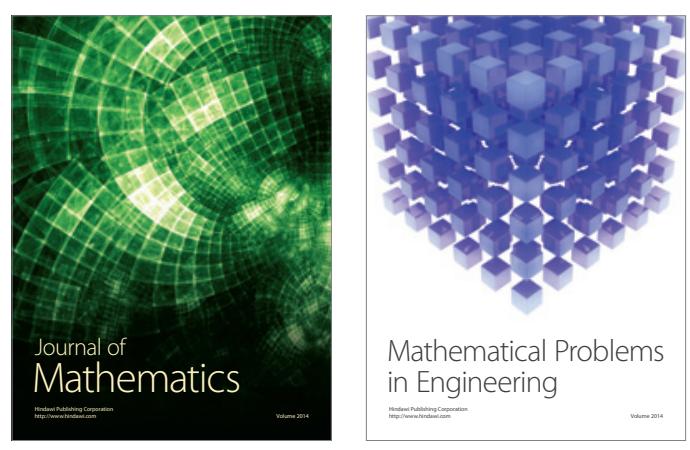

Mathematical Problems in Engineering
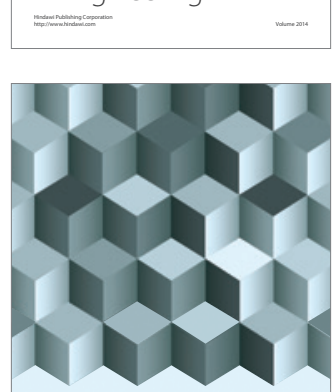

Journal of

Function Spaces
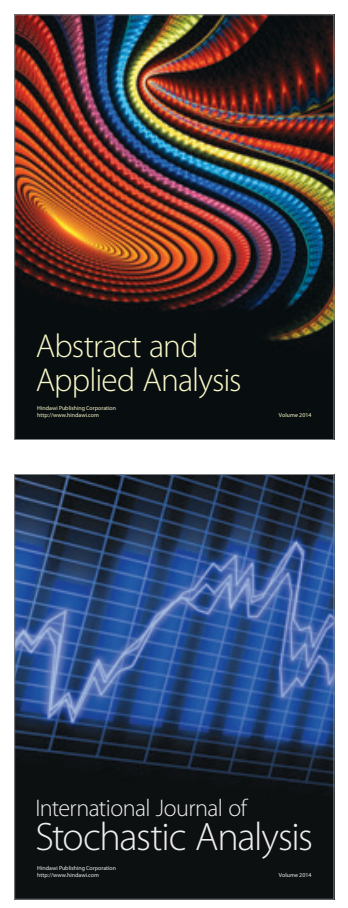

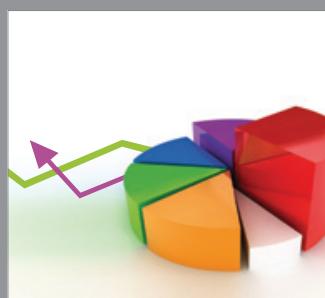

ournal of

Probability and Statistics

Promensencen
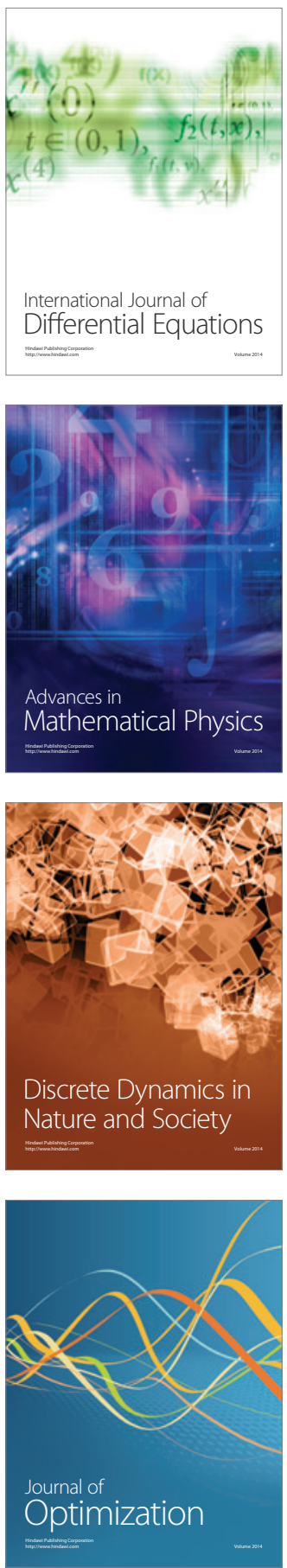